\title{
Expressive Communication Skills in English: A Criterion for Non-Native L2 Students
}

\author{
Tarjani Dakshesh Sheth \\ Teaching Assistant, ASH Department, C.G.P.I.T, Uka Tarsadia University, Bardoli, India \\ Tarjani.sheth@utu.ac.in
}

\begin{abstract}
When learning a foreign language, receptive skills usually come first and should be followed by practical application of expressive ones. If a learning process lacks one of them, the final outcome will not be complete. Expressive skills would only exist with the support of receptive ones. Inbound knowledge symbolises a springboard to active implementation of grammar structures, passive vocabulary lists, heard and repeated sounds of a foreign language. This theoretical background applies to any studied language. This proves that both types of skills-receptive and productive-are inseparable and one cannot exist without the other. This paper discusses the importance of expressive-productive skills in English L2 as outbound skills of knowledge and information for students.
\end{abstract}

Keywords: communication, skill development, productive skills, speaking skills, writing skills.

\section{INTRODUCTION}

As most active users of any foreign language know, speaking and writing are in communal relationship. Undoubtedly, grammatical structures, words and their proper use, and certain extent of accuracy need to be respected. These are implemented in both types of active skills. Expressive skills - also called productive or active skills - mean the dissemination of information that a user yields. When a learner starts learning a foreign language, he surely and subconsciously is exposed to both categories of language skill. Productive/expressive skills are crucial as they give students opportunity to practise real-life activities in the classroom. It is used as a 'barometer' to check students' learning. Teaching speaking is vital as the students are expected to communicate in English. English is used to acquire higher learning. All the students who travel abroad for higher education whether it is medical, business schools or advanced studies their medium of instruction is English. All the Universities and colleges in Australia, The United States, Canada, Great Britain, New Zealand and Singapore which are core attraction for higher studies for International students they teach only in English. All the journals, periodicals and reports that inspire today's scientists, engineers, technologist and technocrats are published in English.

\section{IMPORTANCE}

Reading, writing, listening and speaking are all interrelated in a language learning environment. Literacy is, however, essential for educational success. Productive skills do not exist utterly independently from receptive skills. Passive skills represent an essential part of language skills and basics of some categories of productive skills. Both types of active skills, i.e. speaking and writing share some types of activities and some belong merely to one of them. Nowadays, at the age of the Internet there are more innovative and lively ways to practice active skills. English has become a medium of expression in digital media. However, some of them are accepted only by foreign language users and not by their language instructors. Skill in writing develops only through regular experience of all types of writing. If students are given the opportunity to make choices and decisions about what they do, they will be more motivated to engage with learning activities. Speaking and writing are communicative tasks and imply an audience. Therefore the message must be organised so that it is communicated effectively. A student's language proficiency can vary from class to class in accordance with the type of task and the learning context. It is very important to provide nonjudgemental environment for L2 expressive skills as they are likely to become a target of mockery by fellow students. 


\section{EXPressive Skills - Parameter of Linguistic CoMpetence}

Second Language input is indispensable in the development of linguistic competence. However, a question remains as to how much linguistic input gets retained and how overall SECOND LANGUAGE skills are output dependent. Receptive skills are developed through engaged input. SECOND LANGUAGE proficiency is also exhibited though the expressive modality comprising speaking and writing. All these linguistic components are not mutually independent but interconnected. Although receptive and expressive skills have been characterized separately, it is still unclear how the factor structures of receptive and expressive language skills are related to each other. Reves and Levine (1988) indicated that listening and reading are distinct but similar skills sharing commonalties in integrated and holistic comprehension of the message. Further research studies have suggested crossover and overlap between listening and reading abilities beyond their unique trait of skill operation and function (Bae \& Bachman, 1998).

As Riggenbach and Lazaraton point out, rather than implementing activities that concentrate attention strictly to accuracy, plenty of language instructors focus on promoting communicative competence in language students by applying "communicative activities" (Riggenbach \& Lazaraton, 1991, p.125). The classroom environment and atmosphere definitely create necessary part of successful teaching and learning. These are highly valued by the learners. Creative teachers, who do not want to let their learners to get bored, work with a wide scope of speaking and writing activities. For the teaching purpose, not only lesson plan but also a term syllabus needs to be created in advance. A good teacher figures out what is effective for his students.

\section{Stipulation OF Fluency ANd ACCURACY}

As Olshtain and Cohen state (Olshtain \& Cohen, 1991, p.154),"if we wish to master another language we need to become more communicatively competent". Their observation proves the idea that language accuracy is necessary but not the most vital feature of speaking activities like fluency. To organize the lesson effectively a wide range of diverse activities should be involved in the lesson plan. The teaching experience and long-term observation bring us a long record of activities and exercises in order to practice productive skills effectively. Speaking proves to be one of the main goals when learning English as a foreign language.

With respect to certain factors that may influence the final outcome of the language teaching, the following activities can be used:

- More multifaceted conversation role-plays with stress on proper grammar structures and prolonged vocabulary inventory of certain topics.

- Portrayal of real-life topics and more serious local and global issues in a form of writing tasks.

- Teacher's evaluation and provided feedback.

'Traditionally, the teacher evaluates his learners either by giving grades or verbally'states Riggenbach and Lazaraton; the teacher's feedback involves criteria such as focus on content, i.e. clarity, original idea, organization and delivery of the speech, and whether the goals of the activity were kept. A common tool to collect some information of this kind is to design the evaluation sheet. (Riggenbach and Lazaraton, 1991, p. 129).Besides those previously mentioned traditional activities supporting proficiency of productive skills there are new and modern trends that proved to become very popular with young and middle-aged learners. Not all of them are popular with everybody but some seem to be gaining their audience.

With the development of the Internet services and applications, a number of innovative methods to support productive skills became highly valued and frequently used. Internet provides students with opportunities such as different kinds of social networking, e.g. Facebook, Twitter, LinkedIn, to name a few most common ones. What comes into questions is grammar adequacy, level of vocabulary correctness, less formal English that play their rolesin this format of communication tools without any supervision. Students in their answers also support the idea of joining discussion groups, various interest clubs, real-life conversations that deal with contemporary issues. (Golkova \& Hubackova, 2014, p. 447-481)

Despite this consensus onmulti-dimensional components involved in SECOND LANGUAGE performance, it is not known how many sub skills are involved in SECOND LANGUAGE 
proficiency. At the same time, Reves and Levine (1988) indicate that listening and reading are distinct but similar skills sharing commonalties in integrated and holistic conception of the message.

Recent research has indicated that overall linguistic skills comprise multi-trait or multi-componential sub skills (Bachman \& Palmer, 1981; Sasaki, 1996; Shin, 2005), although receptive and expressive skills have been characterized separately, it is still unclear how the factor structures of receptive and expressive language skills, are related each other. Further research studies have suggested crossover and overlap between listening and reading abilities beyond their unique trait of skill operation and function. (Bae \& Bachman, 1998) It can be said that the amount of fluency and accuracy acquired with receptive skills will shape expressive skills of a student.

\section{Divergence of Sub Skills Required for Developing EXPRESSive SKILls}

The sub skills of Speaking are:

1. Vocabulary

2. Structural accuracy

3. Phonological accuracy

1. The development of new vocabulary is an activity which spans all the skills of language and will be an ongoing challenge for all pupils. Approaches to the development of new vocabulary in the language support class are provided in the teaching cycles above. In addition to the collaborative 'brainstorming' type activities, older pupils and in particular those moving on to post-primary schools in the near future would benefit from practice in using dictionaries effectively.

2. Developing structural accuracy in Speaking is a process that should be accompanied by classroom activities which are guaranteed to involve pupils in contributing to the activity from the earliest stage, even when their contributions may be largely inaccurate. It is important, however, that accuracy is reinforced frequently without putting pupils off communicating. Writing, therefore, becomes most important in the reinforcement of aspects of structure such as sequencing and tenses. Writing and speaking, as a result, are mutually supportive learning activities.

3. Phonological accuracy is critical for accurate spelling. Pronunciation and intonation may be developed through a range of classroom activities. In addition to learning through activities, pupils will also focus on the teacher as a model. It is important, therefore, that the teacher is constantly aware of his/her clarity of pronunciation and of correcting/clarifying pronunciation that is inaccurate.

The sub skills of Writing are:

1. Vocabulary

2. Structural accuracy

3. Orthographic accuracy

1. The development of new vocabulary, as indicated for speaking, is an activity which spans all the skills of language and will be an ongoing challenge for all pupils. Brainstorming activities and dictionary-based activities are both excellent means of leading into a written task. Brainstorming gets the pupils involved in the task from the outset and activates their thoughts and previous learning. Using a dictionary effectively is particularly important for pupils whose literacy in English is at a lower level than the peer group. This skill will transfer into other areas of learning.

2. Developing structural accuracy is particularly important in writing tasks because the pupil has time to work on written text with the objective of producing a perfect final version. Accuracy will automatically be reinforced through comment and feedback from the teacher. The more a language learner, of any age, is encouraged to work at a problem such as a vocabulary item, or a structural/grammatical inaccuracy, the more he/she will retain the information and apply it in the future.

3. The development of orthographic accuracy is particularly important for pupils who do not learn to write in primary school with the peer group. The language support teacher, therefore, has an important role to play both in modelling good handwriting and in correcting what pupils have written and providing further practice as necessary. 


\section{Current Situation}

Most common problems in popular and reputed colleges consist of less input of Expressive skills, as the materials and most of the lesson delivery are in English, mostly receptive skills are made use of by the students. All the materials from explanations on the board to presentations and teacher notes are in English. Students have to read a lot. As the classes are mainly in English, it can be concluded that they make use of listening and note taking, too. However, the only writing they do is for the exams and lab reports, which make the practice of writing quite limited and unsatisfactory. Lab reports are written together by a group of students mostly copying the procedures of the experiment of the day. Students make use of the notes they take during the experiment in class to compose their lab reports. The reports mostly consist of tables and graphics and their explanations underneath, which reduces the amount of writing practice even more. Speaking could be referred to as the most neglected skill in the classrooms as the observers barely observe students speaking in English. They answer in English mostly only if they could be answered in one or two words Moreover, most of the students lack confidence in speaking in English as even if they attempt to ask or answer a question in English by forming a full sentence, they give up the trial quickly and geot back to the safer zone of their native language. Although the students clearly have problems with speaking in English, teachers do not seem to force or encourage students to try to talk in English. Especially the laboratory classes seem like a big opportunity for students to practice by interacting to teachers and to their peers in English as there is real life situation and hands on action already included to make things a little easier and closer to real life experience. All in all, the practice suggests that the primary importance is given to the comprehension of the content not to the acquisition or practice of the language itself.

\section{OBSERVATION}

Communication is all about practice. Existing communication teaching methodology lacks apposite research as concerned to the acquisition of language and its implementation in teaching. Insurrection in the higher educational practice will lead students to subsidise in communicational development courses and the teachers to focus on the requirement for a broader set of educational aptitudes to cope up with the altering educational culture. For teachers, these changes involve the use of new educational training procedures for the course, and ways in which they can support students to upsurge their capability in augmenting their Productive skills in English.

Practice with different native speakers, role play, Group Discussions, Presentations can also enhance expressive skills. Conversation practice with fellow students in controlled environment, listening to subject related talk shows, or radio interviews might help in both ways. When discussing both expressive skills in detail we can assume that developing speaking skill helps as being able to use English to communicate right from the start is highly appealing and inspiring to students. Students enjoy speaking and it is usually the top precedence for them. Speaking activities help the rapport, group dynamics and atmosphere in class. Furthermore, they require students to draw upon what they already know in order to express their ideas. In this way they are always brushing up previous knowledge and putting it into practise with the new information still being assimilated. Finally, speaking is useful for the teacher as it's a good indication of the students' strengths and weaknesses.

Teaching writing is important because written communication is a basic life skill. The amount of time spent on teaching writing will obviously depend on students' needs. Another reason students need to write is for assimilation. Writing is an effective way of strengthening what students have already been studying, and they benefit significantly from seeing new or unacquainted language in written form. Writing is a good way to practise grammar structures; it helps students to acquire new vocabulary and to learn English punctuation rules. It emboldens learner autonomy when students are asked to keep journals or turn in regular writing assignments that they carry out at home.

\section{Conclusion}

To sum up, there is a necessity for English teachers to provide the students skills for oral competence. Moreover, the teaching methodologies of faculty members in colleges teaching communication need to be enriched as a large number of students want more interactive sessions to improve their language skills. It is absolutely necessary to provide environment to ensure a student develop productive skills to express himself impressively. It can be concluded that today's learner has to strive with the world. Upright employees must acquire pioneering skills to express- precise and correct language and effective expression of thoughts. To excel in this viable world, a learner needs to be a multifaceted person. It has now become inexorable for him to develop excellent expressive skills to cope with constant changing world. 


\section{REFERENCES}

Bae, J., \& Bachman, L. F. (1998). A latent variable approach to listening and reading: Testing factorial invariance across two groups of children in the Korean/English two-way immersion program. Language Testing, 15, 380-414.

Golkova, Dita, and Sarka Hubackova."Productive skills in second Language learning." ProcediaSocial and Behavioral Sciences 143 (2014): 477-481.

Reves, T., \& Levine, A. (1988). The FL receptive skills: Same or different? System, 16, 327-336.

Bachman, L. F., \& Palmer, A. S. (1981).The construct validation of the FSI oral interview. Language Testing, 31, 67-86

OlshtainE.,\& Cohen A.D. (1991) Developing a measure of socio cultural competence: The case of apology p.154

Riggenbach, H., \& Lazaraton, A. (1991).Promoting Oral Communication Skills. In M. Celce-Murcia (Ed.), Teaching English as a Second or Foreign Language (pp. 125-136). Los Angeles: University of California.

Oller, J. (1979). Language tests at school: A pragmatic approach. London: Longman https://www. researchgate.net/publication/275544322_Productive_Skills_in_Second_Language_Learning

https://www.scribd.com/document/228429826/Developing-Productive-Skills

Sárosdy, F. \& Tamás, B. (ed). (2006). Applied linguistics for BA students in English. Bolcsesz Konzorcium: Minden Jog Fenntartva.

\section{AUTHOR's BIOGRAPHY}

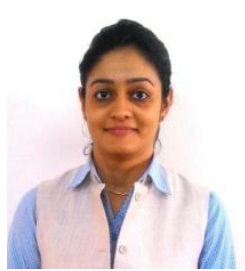

Tarjani Sheth, currently serving as an assistant professor in Chhotubhai Gopalbhai Patel Institute of Technology, received a Bachelor degree in English Language as a Specialist of English Language from South Gujarat University in 1997. From 19971999 she attended Master of Arts Program at English Language Faculty, English Department, where she got a Master of Arts in "English Language and Linguistics". In 2000 she was involved in the B ED program where she received a B ED Degree with specialisation of English Language Teaching. Having 10 years of High school teaching experience, she also received her Diploma in Business Management from Central Queensland University, Australia and was involved with voluntary work of teaching English as a Foreign Language to Adult migrants in Gold Coast Australia until 2012. 